Check for updates

Cite this: RSC Adv., 2018, 8, 37433

Received 7th September 2018 Accepted 20th October 2018

DOI: $10.1039 / c 8 r a 07467 d$

rsc.li/rsc-advances

\section{One-pot synthesis of biodegradable polydopamine-doped mesoporous silica nanocomposites (PMSNs) as pH-sensitive targeting drug nanocarriers for synergistic chemo- photothermal therapy $\dagger$}

\author{
Huicong Zhang, ${ }^{\text {abc }}$ Xuandong Wang, (D)*bc Peiyuan Wang, ${ }^{\mathrm{bc}}$ Rong Liu, ${ }^{\mathrm{abc}}$ \\ Xuemei Hou, ${ }^{\text {bc }}$ Wei Cao, ${ }^{\text {abc }}$ Rong Zhong, ${ }^{\text {abc }}$ Xiaolong Liu (D) ${ }^{\text {bcd }}$ and Yun Zhang ${ }^{\text {kbc }}$
}

\begin{abstract}
Nanomaterials have been widely used as drug carriers in the biomedical field. However, most of them have limited application because of their poor biocompatibility, targeting, and degradability. Therefore, exploring and developing novel drug nanocarriers to overcome these problems has widely attracted attention. In this study, polydopamine-doped mesoporous silica nanocomposites (PMSNs) were controllably synthesized by a one-pot oil-water biphase stratification approach. PMSNs showed good biodegradability in degradation experiments and also proved to have superior biocompatibility toward hepatocellular carcinoma cells (HepG2) compared with mesoporous silica nanoparticles (MSNs). And PMSNs loaded doxorubicin (DOX) (PMSNs@DOX) exhibited a pH-responsive release effect. Meanwhile, compared with PMSNs@DOX, folic acid-modified PMSNs@DOX (PMSNs@DOX(FA) displayed a targeted uptake and higher inhibition of HepG2 cells. Additionally, PMSNsaDOXaFA had excellent ability to kill tumor cells under synergistic chemo-photothermal therapy. Moreover, this synthetic strategy is promising for the fabrication of unique nanocomposites with various functional cores with PMSNs shells for diverse applications.
\end{abstract}

\section{Introduction}

At present, cancer is a serious threat to human health, and traditional chemotherapy is still one of the most common cancer therapy methods. ${ }^{1}$ However, chemotherapy drugs are often considered to easily cause systemic side effects and induce complications to patients when killing cancer cells because of their lack of specificity for cancer cells and their serious toxicity to normal cells and tissues. ${ }^{2,3}$ With the development of nanotechnology, nano-drug carriers provided new routes for solving the problems of serious side effects from chemotherapy. ${ }^{4,5}$ Targeted nano-carriers could indirectly improve the therapy of drug-resisting cancer cells and reduce

${ }^{a}$ College of Life Science, Fujian Agriculture and Forestry University, Fuzhou 350025, China

${ }^{b}$ Key Laboratory of Design and Assembly of Functional Nanostructures, Fujian Institute of Research on the Structure of Matter, Chinese Academy of Sciences, Fuzhou 350002, China.E-mail:wangxd@firsm.ac.cn; zhangy@fjirsm.ac.cn

'Department of Translational Medicine, Xiamen Institute of Rare Earth Materials, Chinese Academy of Sciences, Xiamen 361021, China

${ }^{d}$ The United Innovation of Mengchao Hepatobiliary Technology Key Laboratory of Fujian Province, Mengchao Hepatobiliary Hospital of Fujian Medical University, Fuzhou 350025, China

$\dagger$ Electronic supplementary information (ESI) available. See DOI: $10.1039 / \mathrm{c} 8 \mathrm{ra} 07467 \mathrm{~d}$ the toxicity which chemotherapeutics agents bring to normal cells. Various nanomaterials have taken important roles in the field of drug delivery systems (DDS) such as liposomes, ${ }^{6,7}$ polymers, ${ }^{8,9}$ silica, ${ }^{10}$ and so on. Nano-drug delivery systems can be accurately targeted to transport cancer drugs to a tumor site with effective release to the tumor cells, so that they can enrich the tumor site, and then improve the chemotherapy effect.

Mesoporous silica nanoparticles (MSNs) have attracted great attention as drug nanocarriers because of their advantages of large specific surface area, adjustable pore size, and high drug loading efficiency. ${ }^{\mathbf{1 1 - 1 3}}$ MSNs-based functional nanomaterials have emerged as a novel multifunctional platform for cancer theranostics. ${ }^{\mathbf{1 4 - 1 6}}$ Moreover, MSNs can be often modified with various functional groups as gatekeepers which are responsive to a certain external stimulus for controllable release, ${ }^{17,18}$ such as $\mathrm{pH},{ }^{19,20}$ redox, ${ }^{21}$ light, ${ }^{22,23}$ temperature, ${ }^{24}$ magnetic fields, ${ }^{25}$ and enzymes, ${ }^{26}$ enabling on-command delivery of therapeutic agents. However, stimuli-responsive gated nanocarriers on external surfaces of MSNs coating layer by layer often make the preparation process more complicated along with increasing cost and synthetic steps. Therefore, it is highly desirable to develop novel drug delivery systems based on MSNs with facile preparations, controllable release, and biodegradation for cancer therapy. 
Polydopamine (PDA) is a novel mussel-inspired polymer which can self-polymerize from the dopamine monomer in weakly alkaline conditions. It can be widely used to coat a variety of inorganic or organic materials, with adjustable thickness, reliable stability, and excellent biocompatibility. ${ }^{27,28}$ PDA is often a useful photothermal agent for cancer therapy because it also can convert NIR into heat for killing cancer cells. Thus, PDA has great significance since photothermal therapy can be combined with other therapeutic approaches, resulting in improved therapeutic effects. ${ }^{29}$

Meanwhile, PDA also exhibits $\mathrm{pH}$-sensitive release behavior that is attractive for wide use in biomedical applications. ${ }^{30,31}$ Therefore, it is significant to integrate the advantages of MSNs and PDA in a simple way. In most reported studies, PDA was chosen to coat the surface of mesoporous silica to control drug release. ${ }^{32-34}$ Herein, we developed a facile method for synthesis of PMSNs, which directly doped PDA into MSN nanostructure by a one-pot method. The obtained PMSNs have controllable sizes and pores, and high specific surface areas. Moreover, the PMSNs also display biocompatibility and biodegradability compared to MSNs. Our method can be further applied for coating different cores for core-shell nanostructures synthesis. The surfaces of tumor cells contain many folate receptors, and an exogenous folic acid (FA) could specifically bind to a folate receptor on the surface of a tumor cell and enter the cell by endocytosis. Therefore, the as-prepared nanocomposites can be used as nanocarriers and their surfaces can be further functionalized using the targeting molecule folic acid (FA). ${ }^{35}$ Meanwhile, the drug loading and targeting molecules of modified PMSNs display drug delivery, $\mathrm{pH}$-sensitive drug release, and most importantly, the therapeutic nanoparticles are degradable, indicating that they have potential application for cancer therapy.

\section{Experimental}

\section{Materials}

Hexadecyl trimethyl ammonium chloride (CTAC, 99.0\%) was purchased from Energy Chemical, China. Triethanolamine (TEA, 99.0\%), dopamine hydrochloride (DA. $\mathrm{HCl}, 98 \%$ ), ammonium nitrate $\left(\mathrm{NH}_{4} \mathrm{NO}_{3}, \mathrm{AR}\right)$, cyclohexane, sulfuric acid $\left(\mathrm{H}_{2} \mathrm{SO}_{4}, 98 \%\right)$, sodium nitrate $\left(\mathrm{NaNO}_{3}, 99.0 \%\right)$, potassium permanganate $\left(\mathrm{KMnO}_{4}, \mathrm{AR}\right), \mathrm{H}_{2} \mathrm{O}_{2}$ (AR, 30\%), ammonia solution $\left(\mathrm{NH}_{3} \quad \mathrm{H}_{2} \mathrm{O}, 25-28 \%\right)$, hexadecyl trimethyl ammonium bromide (CTAB, 99.0\%), ascorbic acid (99.99\%), and methanol were all obtained from Aladdin Industrial Corporation, Shanghai. Tetraethyl orthosilicate (TEOS, 99\%), (3-aminopropyl) triethoxysilane (APTES, AR), IGEPAL (CO-520), silver nitrate $\left(\mathrm{AgNO}_{3}, 99 \%\right)$, sodium borohydride $\left(\mathrm{NaBH}_{4}, 99.0 \%\right)$, Gold(III) chloride trihydrate $\left(\mathrm{HAuCl}_{4} \cdot 3 \mathrm{H}_{2} \mathrm{O}, 99.0 \%\right)$, and doxorubicin (DOX) were purchased from Sigma. Folic acid (FA, AR) was obtained from Xiya reagent. Graphite powder (99.9995\%) was purchased from Alfa Aesar. HepG2 cells (hepatocellular carcinoma) were purchased from ATCC (Manassas, VA, USA). DMEM/HIGH glucose and penicillin-streptomycin solutions were purchased from HyClone. Fetal bovine serum (FBS) was obtained from Excell Bio. Phosphate buffered saline (PBS, 10×) was purchased from Solarbio. Cell Counting Kit-8 (CCK-8) and 4',6-diamidino-2-phenylindole (DAPI) were purchased from Dojindo Laboratories (Japan). Ultrapure water with a resistivity of $18.2 \mathrm{M} \Omega \mathrm{cm}$ obtained from Milli-Q Gradient System (Millipore, Bedford, MA, USA) was used for all experiments.

\section{Characterization}

The morphology structure of nanocomposites was characterized by a transmission electron microscopy (TEM) Hitachi $\mathrm{H}$ 7650 system at an accelerating voltage of $100 \mathrm{kV}$. Field emission scanning electron microscopy (FE-SEM) images were taken on a Hitachi S-4800 microscope. UV-Vis spectra were recorded with an Agilent Cary 5000 UV-Vis-NIR Spectrophotometer. Thermal analysis was measured by a Mettler-Toledo TGA/DSC 1 with the heating rate at $10{ }^{\circ} \mathrm{C} \mathrm{min}^{-1}$. The zeta potential of nanocomposites was measured by a Brookhaven Omni analyzer. Nitrogen adsorption-desorption isotherms and pore size distribution curves were performed at $77 \mathrm{~K}$ with a Quantachrome Autosorb iQ2 gas adsorption analyzer; the sample was degassed under vacuum at $200{ }^{\circ} \mathrm{C}$ for $6 \mathrm{~h}$ prior to measurement.

\section{Synthesis of PMSNs}

The PMSNs were synthesized by an oil-water biphase stratification approach according to the method of MSNs with minor modification..$^{36}$ Briefly, $8 \mathrm{~mL}$ of $25 \%$ CTAC aqueous solution was added to $12 \mathrm{~mL}$ of ultrapure water, and then $48 \mu \mathrm{L}$ of TEA was successively added to a $50 \mathrm{~mL}$ round bottom flask, while being rapidly stirred in a water bath at $60{ }^{\circ} \mathrm{C}$ for $1 \mathrm{~h}$. Then, $50 \mathrm{mg}$ of $\mathrm{DA} \cdot \mathrm{HCl}$ was added to the above solution. Subsequently, $10 \mathrm{~mL}$ of $20 \%$ TEOS/cyclohexane solution was slowly added and gently stirred for $12 \mathrm{~h}$. Then, the solution was centrifuged at $16000 \mathrm{rpm}$ for $30 \mathrm{~min}$ and washed with water three times. Finally, the product was dispersed in $0.6 \% \mathrm{NH}_{4} \mathrm{NO}_{3}$ /ethanol solution in a $60{ }^{\circ} \mathrm{C}$ water bath for $12 \mathrm{~h}$ to remove extra template CTAC. After centrifugation, the precipitate was washed with ethanol and water several times, and then the obtained PMSNs were dispersed in water.

\section{Drug loading of PMSNs}

To load the anticancer drug-DOX, $10 \mathrm{~mL}$ of PMSNs $\left(1 \mathrm{mg} \mathrm{mL}{ }^{-1}\right)$ ethanol solution was mixed with $10 \mathrm{~mL}$ of DOX/methanol solution $\left(1 \mathrm{mg} \mathrm{mL}^{-1}\right)$ in a $50 \mathrm{~mL}$ round bottom flask and stirred for $24 \mathrm{~h}$ in the dark at room temperature. After centrifugation, all supernatants were collected and their absorption values were measured by a UV-Vis spectrophotometer; additionally, the precipitate was washed three times with ethanol and dispersed in water to obtain a PMSNs@DOX solution with final concentration of $1 \mathrm{mg} \mathrm{mL} \mathrm{m}^{-1}$. Each experiment was repeated three times.

\section{APTES-functionalization and FA-conjugation of PMSNs@DOX}

Functional folic acid was bound to the surface of the PMSNs. First, PMSNs@DOX was modified by APTES using a specific method is as follows: $10 \mathrm{~mL}$ of PMSNs@DOX $\left(1 \mathrm{mg} \mathrm{mL}^{-1}\right)$ ethanol solution was mixed with $50 \mu \mathrm{L}$ of APTES and kept 
stirring for $12 \mathrm{~h}$ in the dark. And then it was centrifuged and washed several times with ethanol, which prepared it for the next functional modification by folic acid. Then the folic acid/ ethanol solution was mixed with amino-modified PMSNs@DOX and kept stirring for $12 \mathrm{~h}$ in the dark. Lastly, it was centrifuged and washed several times with ethanol and dispersed in water to obtain a PMSNs@DOX@FA solution.

\section{Drug release of PMSNs@DOX}

Investigating the vitro release of DOX from PMSNs was carried out through a dialysis method. Briefly, $5 \mathrm{~mL}$ of $1 \mathrm{mg} \mathrm{mL}$ PMSNs@DOX solution was centrifuged and redispersed with $1 \mathrm{~mL}$ pH 4.0 or pH 6.9 PBS buffer solution, respectively. Then, it was transferred into a dialysis bag $(\mathrm{MWCO}=3500 \mathrm{Da})$ and immersed in $10 \mathrm{~mL}$ of the same release medium, $\mathrm{pH} 4.0$ or $\mathrm{pH}$ 6.9 PBS buffer solution, and incubated at $37{ }^{\circ} \mathrm{C}$ under stirring at $120 \mathrm{rpm}$. To measure the amount of DOX that had been released, all of the outside solutions were withdrawn and replaced with equal volumes of corresponding fresh buffer solutions at various time $(0.5,2,4,8,12,24$, and $48 \mathrm{~h})$. DOX concentration in the withdrawn solution was measured by a UVVis-NIR spectrophotometer (Agilent Cary 5000) with the absorbance at $480 \mathrm{~nm}$, and the release experiments were conducted in triplicate; the cumulative DOX release percentage as a function of time was recorded.

\section{Photothermal property of PMSNs}

To study the photothermal property of MSNs and PMSNs, $1 \mathrm{~mL}$ of MSNs and PMSNs solution with the same concentration $\left(2 \mathrm{mg} \mathrm{mL}{ }^{-1}\right.$ ) were added to each quartz cuvette and exposed to $808 \mathrm{~nm}$ laser radiation at $2 \mathrm{~W} \mathrm{~cm}^{-2}$ for $8 \mathrm{~min}$, respectively. Simultaneously, temperature data was recorded using a thermocouple microprobe.

\section{Cell viability}

Cell toxicity of MSN and PMSNs of HepG2 cells were cultured in DMEM high glucose medium containing $10 \%$ fetal bovine serum (FBS) and $1 \%$ penicillin/streptomycin at $37^{\circ} \mathrm{C}$ under $5 \%$ $\mathrm{CO}_{2}$. The cells $\left(1 \times 10^{4}\right)$ were incubated in each well of a 96-well plate for $24 \mathrm{~h}$, then incubated with MSN or PMSNs of different concentrations $\left(50,100,200,300,400,500\right.$, and $\left.600 \mu \mathrm{g} \mathrm{mL} L^{-1}\right)$ for $24 \mathrm{~h}$. Cell viabilities were studied using a Cell Counting Kit-8 (CCK-8). Enzyme dehydrogenase in living cells was oxidized with this kit to orange carapace. The quality was assessed colorimetrically by using a multi-reader (TECAN, Infinite M200, Germany). The measurements were based on the absorbance values at $450 \mathrm{~nm}$ and the following formula was used to calculate the viability of cell growth:

Viability $(\%)=($ mean absorbance value of treatment group $/$ mean absorbance value of control group) $\times 100$.

For drug targeting and synergistic chemo-photothermal therapy evaluation, PMSNs@DOX and PMSNs@DOX@FA of different concentrations $(50,100,200,300,400,500$, and $600 \mu \mathrm{g}$
$\mathrm{mL}^{-1}$ ) were introduced in a 96-well plate for $24 \mathrm{~h}$, and the PMSNs@DOX@FA treated cells were irradiated by $808 \mathrm{~nm}$ laser ( $2 \mathrm{~W} \mathrm{~cm}^{-2}$ for $3 \mathrm{~min}$ ), and then incubated overnight. The cell viabilities were measured by the CCK-8 assay.

\section{Cellular uptake}

HepG2 cells were incubated by PMSNs@DOX@FA, and HepG2 cells were also incubated with PMSNs@DOX + free FA and PMSNs@DOX, separately, as the control groups and $5 \times 10^{4}$ HepG2 cells were seeded in a cell culture dish. Then, after $24 \mathrm{~h}$ culturing, PMSNs@DOX, PMSNs@DOX@FA and PMSNs@DOX@FA + free FA (300 $\left.\mu \mathrm{g} \mathrm{mL}^{-1}\right)$ were respectively added into fresh medium and incubated for another 1, 2, 4, and $6 \mathrm{~h}$ with cells. After washing with PBS $(1 \times)$ for 3 times, the cells were fixed by $4 \%$ formaldehyde for $10 \mathrm{~min}$. Finally, all nuclei were stained by DAPI $\left(1 \mu \mathrm{g} \mathrm{mL}^{-1}\right)$ after washing 3 times with PBS. Then, all the samples were observed by a confocal laser scanning microscope (CLSM). The fluorescence of DOX (550$650 \mathrm{~nm}$ ) was collected by $488 \mathrm{~nm}$ laser irradiation.

\section{Results and discussion}

\section{Fabrication and characterization of PMSNs}

The synthesis process of PMSNs@DOX@FA and the mechanism of chemotherapy is illustrated in Scheme 1. The PMSNs were synthesized by a one-pot method according to an oil/water biphase approach with minor modifications. ${ }^{36}$ Briefly, in this biphase system, the bottom water phase was a hexadecyl trimethyl ammonium chloride (CTAC) and dopamine hydrochloride $(\mathrm{DA} \cdot \mathrm{HCl})$ aqueous solution and the upper oil phase was a tetraethyl orthosilicate (TEOS)/cyclohexane solution, which was mainly used as the storage medium of silica precursors. CTAC served as a template for formation of the dendritic mesoporous structure, while triethanolamine (TEA) as a catalyst will promote TEOS hydrolysis and provide basic $\mathrm{pH}$ conditions for the formation of polydopamine with dopamine hydrochloride $(\mathrm{DA} \cdot \mathrm{HCl})$ as the precursor. For evaluating the morphology of

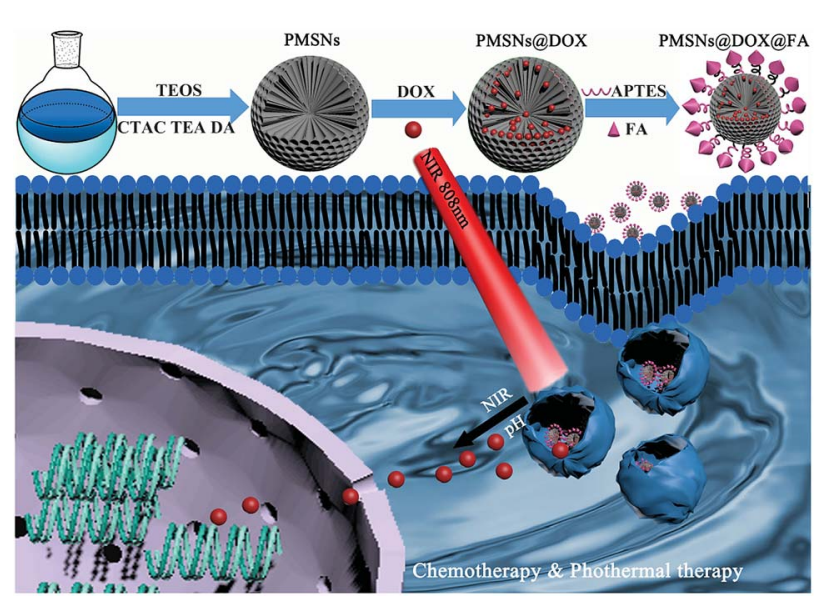

Scheme 1 Schematic illustration of the synthesis process of folic acid modified and DOX loading PMSNs nanocomposites and the mechanism of drug delivery for synergistic chemo-photothermal therapy. 
PMSNs, the transmission electron microscopy (TEM) revealed the changes of PMSNs with different DA contents for various times. As shown in Fig. 1a-c, with an increase of $\mathrm{DA} \cdot \mathrm{HCl}$ content, the dendritic structure of PMSNs became sparser and the pore size turned larger. This is mainly owing to the increase in the amount of $\mathrm{DA} \cdot \mathrm{HCl}$, resulting in more PDA nanoparticles generated while less CTAC and TEOS resulted on each PDA. When the reaction time increased from $6 \mathrm{~h}$ to $12 \mathrm{~h}$, the PMSNs size became larger and the morphology was also more uniform and dense (Fig. 1d-f). We found that the morphology of PMSNs could be controlled by adjusting the dosage of $\mathrm{DA} \cdot \mathrm{HCl}$ and reaction time. To prove the stability of PMSNs in water, tests for stability of PMSNs were carried out; PMSNs were dispersed in water and kept for 144 days. As is shown in Fig. S1, $\dagger$ the nanostructure of PMSNs kept in water for 144 days had no obvious change from the 1 day PMSNs, which demonstrated that PMSNs had excellent long-term stability in water.

To further demonstrate that PMSNs were successfully synthesized, the UV-Vis spectra of MSN and PMSNs were carried out. As shown in Fig. 2a, dopamine has a strong UV absorption characteristic peak at $280 \mathrm{~nm}$, while the PMSNs have no obvious characteristic absorption peak at $280 \mathrm{~nm}$, indicating that the DA polymerization was formed from PDA. To further quantify the content of PDA in PMSNs, thermo gravimetric analysis (TGA) of MSNs and PMSNs were studied. ${ }^{37}$ As shown in Fig. $2 \mathrm{~b}$, the weight loss of $7.4 \%$ from 100 to $300{ }^{\circ} \mathrm{C}$ is attributed to gasification of small molecules such as water. When the temperature rose to $811.9{ }^{\circ} \mathrm{C}$, the total weight loss of MSN and PMSNs was $12.07 \%$ and $14.47 \%$, respectively. Therefore, excessive $2.40 \%$ weight loss of PMSNs was due to PDA, stemming from the decomposition of PDA. As polydopamine also has an absorption in the near infrared (NIR) region, the photothermal curve of MSNs and PMSNs enabled us to measure their photothermal properties. Fig. 2c shows that both MSN and PMSNs were irradiated with $808 \mathrm{~nm}$ NIR laser at $2 \mathrm{~W}$ for $8 \mathrm{~min}$. The results exhibit that the temperature of PMSNs increased by $28.2^{\circ} \mathrm{C}$, while the MSN increased by only $5.8{ }^{\circ} \mathrm{C}$. Furthermore, the inserted picture of the MSNs and PMSNs solution indicated that

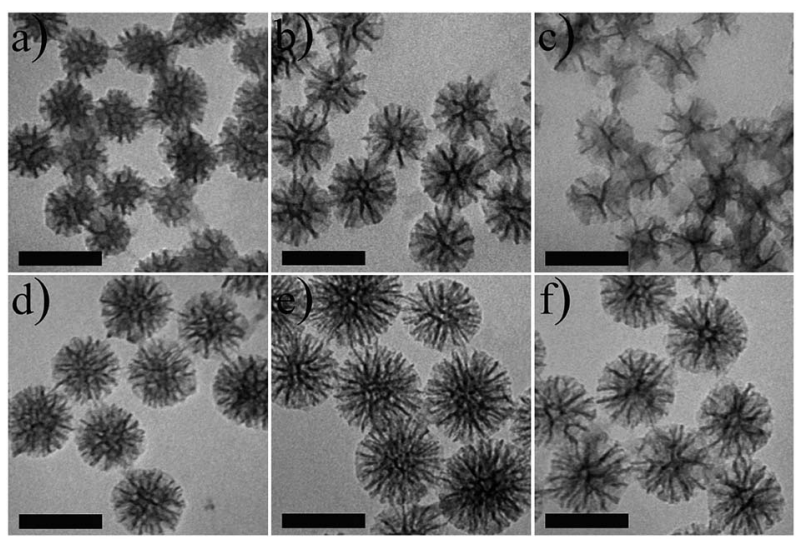

Fig. 1 TEM images of PMSNs prepared with different contents of $\mathrm{DA} \cdot \mathrm{HCl}, 25 \mathrm{mg}$ ( $\mathrm{a}$ and d), $50 \mathrm{mg}$ ( $\mathrm{b}$ and e), $100 \mathrm{mg}$ (c and f) for reaction times of $6 \mathrm{~h}(\mathrm{a}-\mathrm{c})$ and $12 \mathrm{~h}(\mathrm{~d}-\mathrm{f})$, respectively. Scale bar is $100 \mathrm{~nm}$.
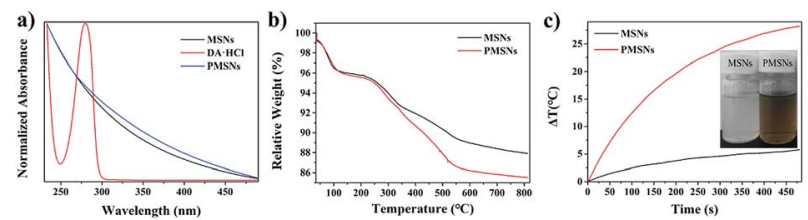

Fig. 2 (a) UV-Vis spectra of MSN, DA. HCl and PMSNs; (b) TGA curve of MSNs and PMSNs; (c) photothermal heating curves of MSNs and PMSNs (MSNs and I PMSNs solution with the same concentration were exposed to $808 \mathrm{~nm}$ NIR laser radiation at $2 \mathrm{~W} \mathrm{~cm}^{-2}$ for $8 \mathrm{~min}$ ). Inset, the solutions of MSNs and PMSNs.

PMSNs were more efficient for photothermal therapy after NIR laser exposure. ${ }^{38}$

Encouraged by the above results, the specific surface area of PMSNs was investigated. As shown in Fig. 3, the adsorptiondesorption isotherm of the PMSNs exhibit a type IV curve with a characteristic hysteresis loop, indicating the mesoporous structure of PMSNs. The specific surface area and the average pore diameter of the PMSNs were $539.9 \mathrm{~m}^{2} \mathrm{~g}^{-1}$ (Fig. 3a) and $7.8 \mathrm{~nm}$ (Fig. 3b), which is close to MSNs, ${ }^{39}$ as calculated by the Brunauer-Emmett-Teller (BET) model and the Barrett-JoynerHalenda (BJH) method, ${ }^{37,40}$ respectively. A field emission scanning electron microscopy (FE-SEM) image of the PMSNs is shown in the illustration of Fig. 3a where the mesoporous pore structure of PMSNs can be obviously seen.

In order to demonstrate PMSNs drug loading content (LC) and release performance, the UV-Vis absorption spectra of PMSNs, free DOX, and PMSNs@DOX were measured. After drug loading of PMSNs, all supernatants were collected and their absorption values were measured by a UV-Vis spectrophotometer. Concentrations of DOX in the solutions were calculated through the calibration curve. The loading content (LC) of the DOX-loaded PMSNs was calculated according to the following equation:
LC $(\%)=($ weight of total DOX - weight of DOX in supernatant $) /$ weight of PMSNs@DOX $\times 100 \%$.

And the calculated LC was $12.52 \pm 0.6 \%$.

As shown in Fig. 4a, free DOX has a strong UV-Vis absorption characteristic peak at $480 \mathrm{~nm}$, while there was no peak with PMSNs; after loading DOX, the UV-Vis absorption of
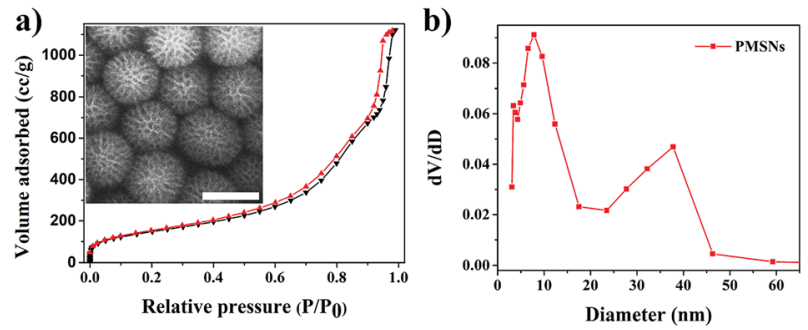

Fig. 3 (a) Nitrogen adsorption-desorption isotherms of the PMSNs with the inset SEM image of the PMSNs. Scale bar is $100 \mathrm{~nm}$; (b) pore size distribution of PMSNs. 

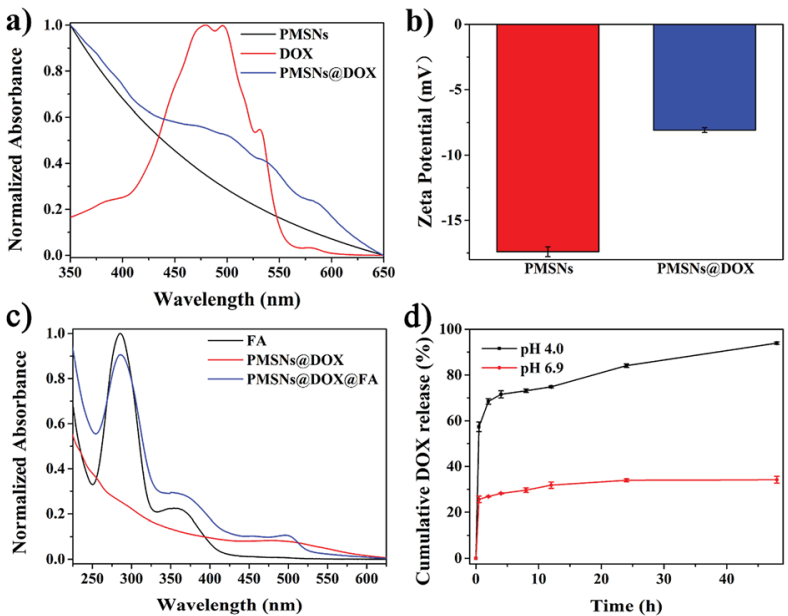

Fig. 4 (a) UV-Vis absorption spectra of PMSNs, DOX, and PMSNs@DOX; (b) zeta potentials of the PMSNs and PMSNs@DOX; (c) UV-Vis absorption spectra of FA, PMSNs@DOX, and PMSNs@DOX@FA; (d) in vitro drug release kinetic profiles of PMSNs@DOX in $\mathrm{pH} 4.0$ and $\mathrm{pH}$ 6.9 PBS buffer solutions, respectively.

PMSNs@DOX at $480 \mathrm{~nm}$ was obviously enhanced, indicating that DOX had been successfully loaded on the PMSNs. Furthermore, the UV-Vis absorption spectra of FA-modified PMSNs@DOX nanocomposites were also measured and they contained both the FA and DOX curves, suggesting the FA successfully modified PMSNs@DOX (Fig. 4c). In addition, zeta potentials of PMSNs and PMSNs@DOX were tested (Fig. 4b). In contrast to PMSNs with the zeta potential of $-17.41 \pm 0.38 \mathrm{mV}$, the value of the zeta potential of PMSNs@DOX was changed into $-8.08 \pm 0.18 \mathrm{mV}$, which further indicated the presence of DOX in the PMSNs.

The effect of the $\mathrm{pH}$-sensitive DOX release manner in PMSNs@DOX mainly contained two factors. On the one hand, was the protonation of amine groups of PDA nanoscaffolds and/ or the DOX molecules in acidic condition, which partially destroys the $\pi-\pi$ or hydrogen bonding interactions between PDA and drugs. ${ }^{41}$ The solubility of DOX is inversely proportional to the $\mathrm{pH}$ value of a solution, so the acidic condition facilitates the diffusion of DOX from pores into the medium; thus, the amount of release and the release rate are improved. ${ }^{42}$ On the other hand, it was reported that PDA has a certain degree of degradation under acidic conditions. ${ }^{33}$ When the PMSNs dispersed in an acidic tumor microenvironment, the PDA nanoscaffolds of PMSNs were degraded and DOX was released from PMSNs. Therefore, DOX can be a successfully triggered release from PMSNs@DOX in an acidic environment, which simulates the tumor microenvironment in vivo and enhances cancer therapy. To further study the effect of $\mathrm{pH}$ on the release of DOX from PMSNs, they were incubated at $\mathrm{pH}$ values of 4.0 and 6.9 in PBS buffer solutions. As shown in Fig. 4d, the release of PMSNs@DOX is pH sensitive and the cumulative DOX release rates were $93.94 \%$ and $34.17 \%$ at $\mathrm{pH} 4.0$ and $\mathrm{pH}$ 6.9, respectively, during $48 \mathrm{~h}$ which indicated an excellent $\mathrm{pH}$-responsive release effect.

\section{Growth PMSNs surface on various substrates}

The oil-water biphase approach also could be used to coat various other nanomaterials. Silica nanoparticles, graphene oxide, and gold nanorods were chosen as cores to demonstrate the feasibility and versatility of this epitaxial growth strategy for coating PMSNs. As shown in Fig. 5, the outer surfaces of core nanoparticles were coated with a PMSNs shell. They used the same synthesis process as PMSNs, except for addition of the $\mathrm{SiO}_{2}$ nanoparticles, graphene oxide (GO), and gold nanorods (GNRs) simultaneously with CTAC and TEA to obtain the $\mathrm{SiO}_{2} @$ PMSNs (Fig. 5a), GO@PMSNs (Fig. 5b), and GNRs@PMSNs (Fig. 5c), demonstrating that this strategy could be widely used to coat various functional cores for biomedical applications.

\section{In vitro biodegradability of MSNs and PMSNs}

MSNs have been widely used as drug nanocarriers due to their high specific surface areas and good biocompatibility. However, the major problem for limiting their biomedical application is biodegradability. To further confirm the biodegradability behavior of PMSNs, the MSNs and PMSNs were dispersed in PBS buffers of pH 5.6 and pH 7.4 for 14 days. As shown in Fig. 6, it is seen from the TEM images that the frameworks were degraded and the pore channels were partly destroyed at pH 5.6 for 9 days, and most frameworks were degraded to a pasty-like structure at 14 days. The frameworks of MSNs partly changed at 14 days in a pH 5.6 PBS buffer solution, while the frameworks were slower to degrade at $\mathrm{pH} 7.4$ than at $\mathrm{pH}$ 5.6. This result indicates that PMSNs can act as nanocarriers with a $\mathrm{pH}$-triggered release.

\section{In vitro cytotoxicity using CCK-8 assay}

To investigate the cytotoxicity of PMSNs, cytotoxicity tests were measured with a CCK-8 kit assay. Fig. 7a shows that both MSN and PMSNs had good biocompatibility with HepG2 cells from a range of 50 to $600 \mu \mathrm{g} \mathrm{mL} \mathrm{mL}^{-1}$ of PMSNs where cell viability was more than $90 \%$. Meanwhile, compared with MSNs, the PMSNs had superior biocompatibility. Compared with PMSNs, PMSNs loaded with doxorubicin (DOX) (PMSNs@DOX) showed much higher cancer cell toxicity, suggesting great potential for biological applications (Fig. 7a). In general, nanomaterials should be designed to enter cells efficiently to realize a better therapeutic effect. Based on this, folic acid (FA) was latterly modified on PMSNs@DOX (PMSNs@DOX@FA) for cellular targeting enhancement. To evaluate in vitro targeting efficiency and

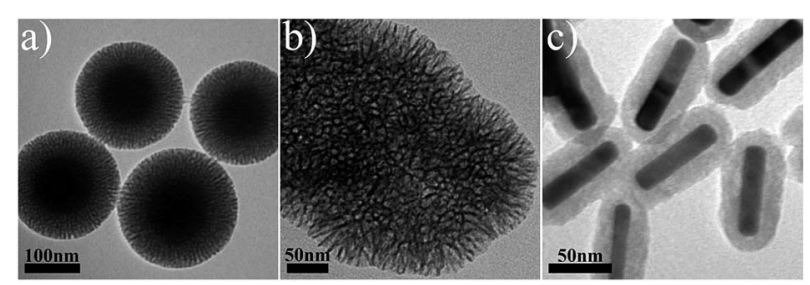

Fig. 5 TEM images of PMSNs coated on surfaces of various nanoparticles: (a) $\mathrm{SiO}_{2}$ @PMSNs, (b) GO@PMSNs and (c) GNRs@PMSNs. 


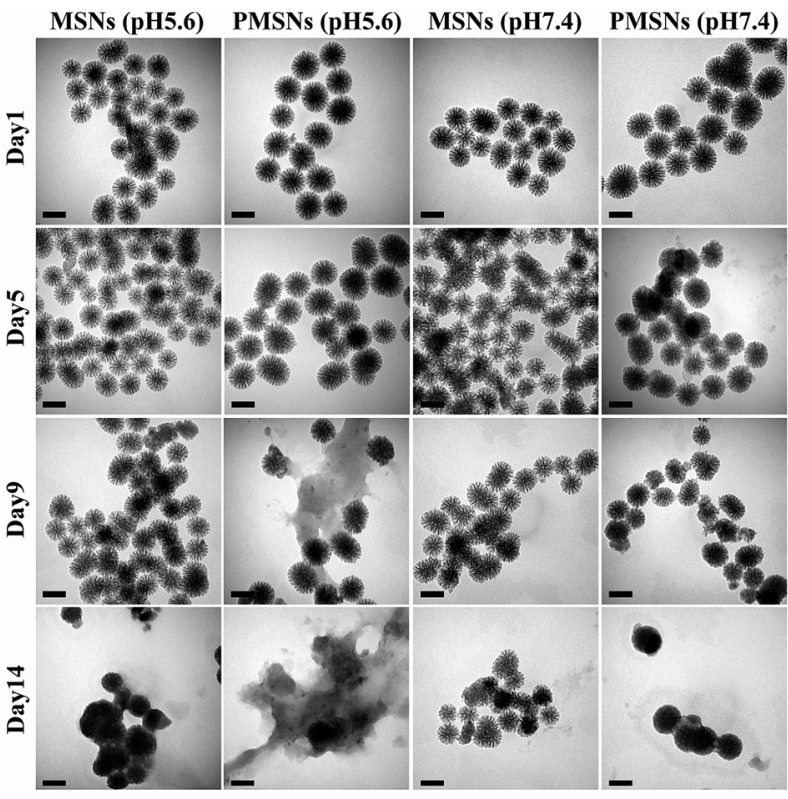

Fig. 6 TEM images of MSNs and PMSNs dispersed in $\mathrm{pH} 5.6$ and $\mathrm{pH} 7.4$ PBS buffers and stirred at room temperature for different days ( $1 \mathrm{~d}, 5 \mathrm{~d}$, $9 \mathrm{~d}$, and $14 \mathrm{~d}$ ). All scale bars represent $100 \mathrm{~nm}$.
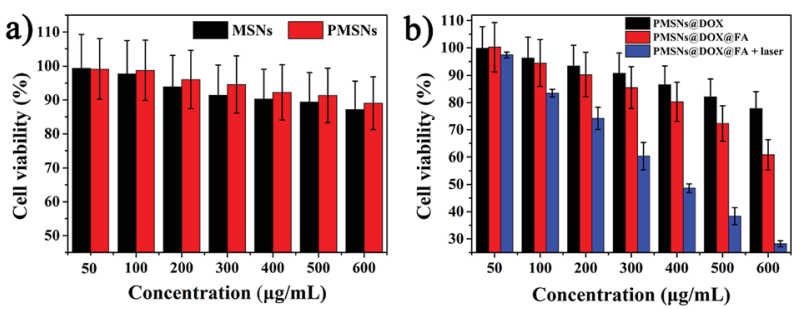

Fig. 7 Cell viability of HepG2 cells after incubation with different concentrations of (a) MSNs and PMSNs, (b) PMSNs@DOX, PMSNsaDOX@FA, and PMSNsaDOXaFA with an $808 \mathrm{~nm}$ laser from 50 to $600 \mu \mathrm{g} \mathrm{mL}^{-1}$

cellular killing ability of PMSNs@DOX@FA against HepG2, the cytotoxicity results showed that, compared with PMSNs@DOX, PMSNs@DOX@FA has significant cell killing ability. The lowest cell viability $(60 \%)$ as well as the most significant cellular apoptosis/necrosis were achieved with PMSNs@DOX@FA 600 $\mu \mathrm{g} \mathrm{mL}{ }^{-1}$ after incubating with HepG2 for $4 \mathrm{~h}$ (Fig. 7b). However, the inhibition rate of PMSNs@DOX was only 20\%, demonstrating that PMSNs@DOX@FA has a superior targeting effect which can significantly improve chemotherapy efficiency. To investigate the synergistic effects of thermotherapy and chemotherapy, the cell viability of HepG2 with PMSNs@DOX@FA + laser groups was only 28\%, which was significantly lower than those of the cells in nonradiated groups, especially when the concentration achieved $600 \mu \mathrm{g}$ $\mathrm{mL}^{-1}$ (Fig. 7b). This result means, compared to chemotherapy alone, PMSNs@DOX@FA with laser irradiation can significantly enhance an antitumor effect, resulting from the photothermal therapy of PMSNs.
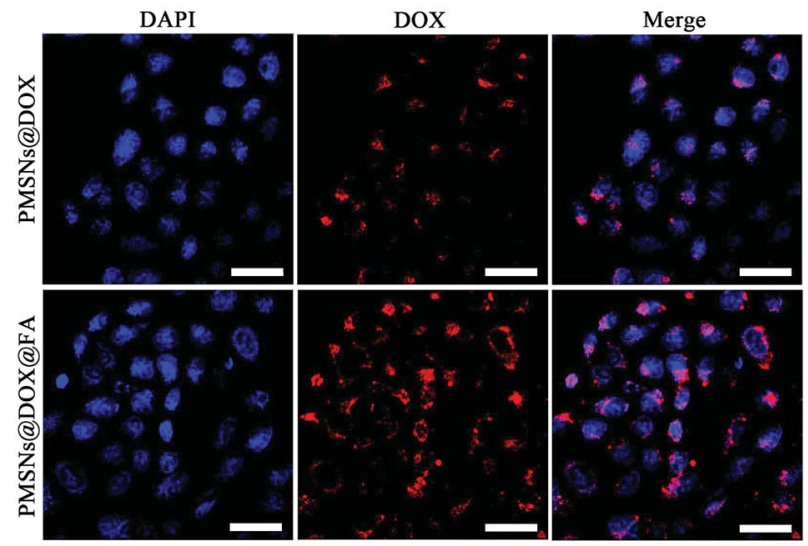

Fig. 8 CLSM-images of HepG2 cells incubated with PMSNs@DOX and PMSNs@DOX@FA; for each series, images from left to right can be classified to the cells in the nuclei of cells (blue, being stained by DAPI), DOX fluorescence in cells (red), and the merged images of DAPI (blue) and DOX (red), respectively. Scale bar is $100 \mu \mathrm{m}$.

\section{In vitro cellular uptake of PMSNs}

Encouraged by the above cellular killing results of PMSNs@DOX@FA, to further validate the important role of FA in the cellular uptake of PMSNs, HepG2 cells were incubated with PMSNs@DOX and PMSNs@DOX@FA for 2 h. As shown in Fig. 8, the fluorescence intensity of DOX in PMSNs@DOX@FA was significantly higher than that of PMSNs@DOX, resulting from more nanocomposites uptaking than that of PMSNs@DOX. This result further indicates FA modified on the surfaces of PMSNs could enhance cellular uptake which agrees with the cytotoxicity results of PMSNs@DOX@FA. And as shown in Fig. S2, $\uparrow$ the fluorescence intensity of DOX in PMSNs@DOX + free FA was similar to PMSNs@DOX, which further indicated

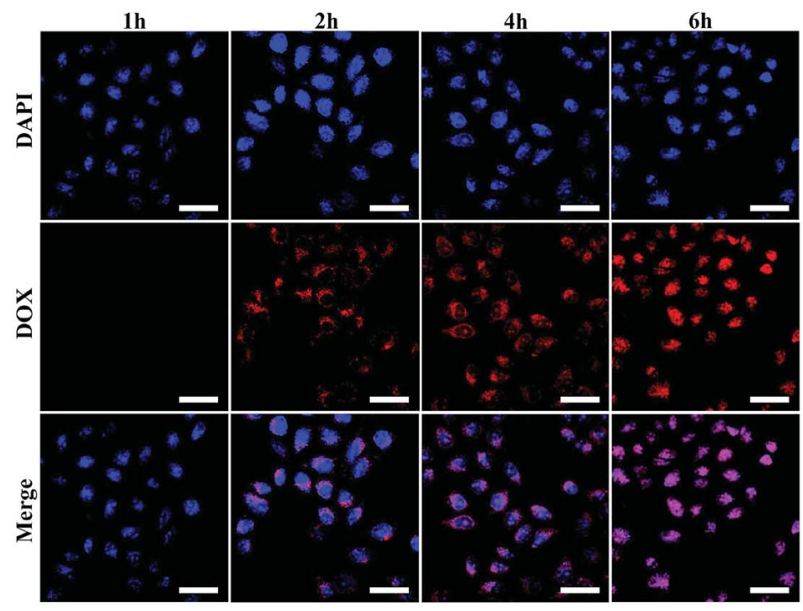

Fig. 9 CLSM images of HepG2 cells after being incubated with PMSNs@DOX@FA for different times ( 1 h, 2 h, 4 h, and 6 h). For each series, images from top to bottom can be classified to the cells in the nuclei of cells (blue, being stained by DAPI), DOX fluorescence in cells (red), and the merged images of DAPI (blue) and DOX (red), respectively. Scale bars, $100 \mu \mathrm{m}$. 
that FA modified on the surfaces of the PMSNs could promote cellular uptake. ${ }^{\mathbf{4 3}}$

To further investigate the cellular uptake and intracellular drug release process of PMSNs@DOX@FA, DOX fluorescence in HepG2 cells was examined by using CLSM after incubating with PMSNs@DOX@FA for various hours (Fig. 9). The intensity of DOX gradually increased in the cytoplasm when the incubation time was $2 \mathrm{~h}$. Later, the signals were detected in whole cells after $4 \mathrm{~h}$ incubation. Finally, all red fluorescence was observed in the nuclei when the incubation time increased from $4 \mathrm{~h}$ to $6 \mathrm{~h}$, indicating that the DOX delivered by PMSNs@DOX@FA can pass through the cytomembrane, assemble in cytoplasm, then pass through the nucleus membrane, and eventually assemble in a nucleus to kill cells. This result indicates that PMSNs@DOX@FA could be used as a targeted drug delivery nanocarrier for cancer therapy.

\section{Conclusions}

In summary, polydopamine-doped mesoporous silica nanocomposites (PMSNs) were successfully fabricated by a facile one-pot oil/water biphase stratification approach. They were demonstrated to have good biocompatibility and biodegradability and were also proved to have lower cytotoxicity compared with mesoporous silica nanoparticles (MSNs) at a concentration range from 100 to $600 \mu \mathrm{g} \mathrm{mL}^{-1}$. The frameworks also could be obviously degraded in PBS buffer solutions of pH 5.6 over 14 days. PMSNs-loaded DOX exhibited a pH-responsive release effect in pH 4.0 buffer solution. The folic acid-modified PMSNs has a targeted intake, with excellent synergistic chemophotothermal therapy and higher inhibition of HepG2 cells. Furthermore, this strategy could also be used for coating various nanomaterials with PMSNs to improve biomedical applications.

\section{Conflicts of interest}

There are no conflicts to declare.

\section{Acknowledgements}

The work was supported by the National Natural Science Foundation of China (No. 61605209), Science and Technology Service Network Initiative Foundation of CAS (No. 2016T3009), Pilot Project of Fujian Province of China (No. 2017Y0084), Selfcreated Area Project of Major Science Technology Innovation Platform of Xiamen (No. 3502ZCQ20171002) and Project of Collaborative Innovation of Industry-University-Research Institute and Science and Technology Cooperation of Xiamen (No. 3502Z20182021).

\section{Notes and references}

1 C. P. Wu, C. H. Hsieh and Y. S. Wu, Mol. Pharm., 2011, 8, 1996-2011.

2 C. G. Martin, E. B. Rubenstein, L. S. Elting, Y. J. Kim and D. Osoba, Cancer, 2003, 98, 645-655.
3 C. J. Dunnill, W. Al-Tameemi, A. Collett, I. S. Haslam and N. T. Georgopoulos, Oncologist, 2018, 23, 84-96.

4 S. Hema, S. Thambiraj and D. R. Shankaran, J. Nanosci. Nanotechnol., 2018, 18, 5171-5191.

5 J. Tang, R. Zhang, M. Guo, L. Shao, Y. Liu, Y. Zhao, S. Zhang, Y. Wu and C. Chen, Biomaterials, 2018, 167, 205-215.

6 W. T. Al-Jamal and K. Kostarelos, Acc. Chem. Res., 2011, 44, 1094-1104.

7 L. Belfiore, D. N. Saunders, M. Ranson, K. J. Thurecht, G. Storm and K. L. Vine, J. Controlled Release, 2018, 277, 1-13.

8 A. Kumari, S. K. Yadav and S. C. Yadav, Colloids Surf., B, 2010, 75, 1-18.

9 N. Nasongkla, E. Bey, J. Ren, H. Ai, C. Khemtong, J. S. Guthi, S.-F. Chin, A. D. Sherry, D. A. Boothman and J. Gao, Nano Lett., 2006, 6, 2427-2430.

10 E. Bagheri, L. Ansari, K. Abnous, S. M. Taghdisi, F. Charbgoo, M. Ramezani and M. Alibolandi, J. Controlled Release, 2018, 277, 57-76.

11 Q. He and J. Shi, Adv. Mater., 2014, 26, 391-411.

12 F. Tang, L. Li and D. Chen, Adv. Mater., 2012, 24, 1504-1534. 13 J. Lu, M. Liong, J. I. Zink and F. Tamanoi, Small, 2007, 3, 1341-1346.

14 Z. Wang, D. Shao, Z. Chang, M. Lu, Y. Wang, J. Yue, D. Yang, M. Li, Q. Xu and W. F. Dong, ACS Nano, 2017, 11, 1273212741.

15 D. Shao, M. Li, Z. Wang, X. Zheng, Y. H. Lao, Z. Chang, F. Zhang, M. Lu, J. Yue, H. Hu, H. Yan, L. Chen, W. F. Dong and K. W. Leong, Adv. Mater., 2018, 1801198.

16 D. Shao, J. Li, X. Zheng, Y. Pan, Z. Wang, M. Zhang, Q. X. Chen, W. F. Dong and L. Chen, Biomaterials, 2016, 100, 118-133.

17 H. Mekaru, J. Lu and F. Tamanoi, Adv. Drug Delivery Rev., 2015, 95, 40-49.

18 A. F. Moreira, D. R. Dias and I. J. Correia, Microporous Mesoporous Mater., 2016, 236, 141-157.

19 P. Du, X. Zhao, J. Zeng, J. Guo and P. Liu, Appl. Surf. Sci., 2015, 345, 90-98.

20 P. Bilalis, L.-A. Tziveleka, S. Varlas and H. Iatrou, Polym. Chem., 2016, 7, 1475-1485.

21 Z. Luo, K. Cai, Y. Hu, L. Zhao, P. Liu, L. Duan and W. Yang, Angew. Chem., Int. Ed., 2011, 50, 640-643.

22 J. L. Vivero-Escoto, I. I. Slowing, C.-W. Wu and V. S. Y. Lin, J. Am. Chem. Soc., 2009, 131, 3462-3463.

23 Y. Tang, H. Hu, M. G. Zhang, J. Song, L. Nie, S. Wang, G. Niu, P. Huang, G. Lu and X. Chen, Nanoscale, 2015, 7, 6304-6310. 24 Q. Lei, W. X. Qiu, J. J. Hu, P. X. Cao, C. H. Zhu, H. Cheng and X. Z. Zhang, Small, 2016, 12, 4286-4298.

25 E. Guisasola, L. Asin, L. Beola, J. M. de la Fuente, A. Baeza and M. Vallet-Regi, ACS Appl. Mater. Interfaces, 2018, 10, 12518-12525.

26 Y. Liu, X. Ding, J. Li, Z. Luo, Y. Hu, J. Liu, L. Dai, J. Zhou, C. Hou and K. Cai, Nanotechnology, 2015, 26, 145102.

27 H. Lee, S. M. Dellatore, W. M. Miller and P. B. Messersmith, Science, 2007, 318, 426-430.

28 Y. Liu, K. Ai and L. Lu, Chem. Rev., 2014, 114, 5057-5115.

29 R. Mrowczynski, ACS Appl. Mater. Interfaces, 2018, 10, 75417561. 
30 F.-F. Cheng, J.-J. Zhang, F. Xu, L.-H. Hu, E. S. Abdel-Halim and J.-J. Zhu, J. Biomed. Nanotechnol., 2013, 9, 1155-1163.

31 W. Zong, Y. Hu, Y. Su, N. Luo, X. Zhang, Q. Li and X. Han, J. Microencapsulation, 2016, 33, 257-262.

32 Q. Zheng, T. Lin, H. Wu, L. Guo, P. Ye, Y. Hao, Q. Guo, J. Jiang, F. Fu and G. Chen, Int. J. Pharm., 2014, 463, 22-26.

33 D. Chang, Y. Gao, L. Wang, G. Liu, Y. Chen, T. Wang, W. Tao, L. Mei, L. Huang and X. Zeng, J. Colloid Interface Sci., 2016, 463, 279-287.

34 W. Cheng, J. Nie, L. Xu, C. Liang, Y. Peng, G. Liu, T. Wang, L. Mei, L. Huang and X. Zeng, ACS Appl. Mater. Interfaces, 2017, 9, 18462-18473.

35 G. Li, Y. Yang, R. Zhou, F. Meng and X. Li, J. Curr. Chem. Pharm. Sci., 2018, 123, 249-259.

36 D. Shen, J. Yang, X. Li, L. Zhou, R. Zhang, W. Li, L. Chen, R. Wang, F. Zhang and D. Zhao, Nano Lett., 2014, 14, 923932.
37 Q. L. Li, S. H. Xu, H. Zhou, X. Wang, B. Dong, H. Gao, J. Tang and Y. W. Yang, ACS Appl. Mater. Interfaces, 2015, 7, 2865628664.

38 Y. Xing, J. Zhang, F. Chen, J. Liu and K. Cai, Nanoscale, 2017, 9, 8781-8790.

39 C. Liang, H. Wang, M. Zhang, W. Cheng, Z. Li, J. Nie, G. Liu, D. Lian, Z. Xie, L. Huang and X. Zeng, J. Colloid Interface Sci., 2018, 525, 1-10.

40 G. Cheng, M. D. Zhou and S. Y. Zheng, ACS Appl. Mater. Interfaces, 2014, 6, 12719-12728.

41 X. Wang, J. Zhang, Y. Wang, C. Wang, J. Xiao, Q. Zhang and Y. Cheng, Biomaterials, 2016, 81, 114-124.

42 X. Li, C. Xie, H. Xia and Z. Wang, Langmuir, 2018, 34, 99749981.

43 L. Tong, W. Chen, J. Wu and H. Li, Anticancer Drugs, 2014, 25, 244-254. 